\title{
Motion - Colonoscopic surveillance is more cost effective than colectomy in patients with ulcerative colitis: Arguments against the motion
}

\author{
Anders Ekbom MD PhD ${ }^{1,2}$
}

\begin{abstract}
A Ekbom. Motion - Colonoscopic surveillance is more cost effective than colectomy in patients with ulcerative colitis: A rguments against the motion. C an J Gastroenterol 2003;17(2):122-124.
\end{abstract}

There are insufficient data upon which to base recommendations about surveillance colonoscopy and prophylactic colectomy for the prevention of colorectal cancer in patients with ulcerative colitis. Case series, analyses of intermediate results and extrapolations from other patient groups do not constitute reliable evidence. A vailable studies are susceptible to several biases: the 'healthy worker' effect, surveillance bias and selection bias. Patients who are enrolled in surveillance programs are more likely to be thoroughly evaluated beforehand, are more likely to be given a diagnosis of dysplasia or neoplasm even when asymptomatic and are more likely to comply with medical treatment, including maintenance anti-inflammatory medication. Comparisons of the rates of neoplasia or death between surveyed and nonsurveyed patients are, therefore, of questionable validity. Prophylactic colectomy, unlike surveillance colonoscopy, prevents death from colorectal cancer. M oreover, it is difficult to keep patients in surveillance programs, and those who withdraw from programs appear to be at high risk of developing cancer. Prophylactic colectomy should be strongly considered for patients with dysplasia, sclerosing cholangitis, longstanding pancolitis (especially if it began early in life) or a positive family history of colorectal cancer. This procedure is underused in clinical practice and is a good alternative to colonoscopic surveillance in high risk patients.

Key W ords: C olonoscopy; C ost effective; U Icerative colitis

\section{M otion - La surveillance par coloscopie est plus rentable que la colectomie chez les patients atteints de rectocolite hémorragique : A rguments contre la motion}

\begin{abstract}
RESU ME : II n'existe pas suffisamment de données permettant de formuler des recommandations sur la coloscopie de contrôle et la colectomie prophylactique pour la prévention du cancer colorectal chez les patients atteints de rectocolite hémorragique. Des séries de cas, des analyses de résultats intermédiaires et des extrapolations à partir d'autres groupes de patients ne constituent pas des sources fiables de données. Les études actuelles sont susceptibles de biais : effet du "travailleur bien portant ", biais de surveillance, biais de sélection. II y a de fortes chances que les sujets qui participent aux programmes de surveillance soient soumis au préalable à une évaluation complète, reçoivent un diagnostic de dysplasie ou de néoplasme même avant l'apparition de symptômes ou respectent le traitement médical, y compris la prise d'anti-inflammatoires d'entretien. Les comparaisons des taux de néoplasie et de mortalité entre patients étudiés et patients non étudiés soulèvent donc des doutes. La colectomie prophylactique, contrairement à la coloscopie de contrôle, prévient la mort attribuable à un cancer colorectal. De plus, il est difficile de garder les patients dans les programmes de surveillance et ceux qui s'en retirent semblent fortement prédisposés au cancer. La colectomie prophylactique devrait être sérieusement envisagée chez les patients qui présentent une dysplasie, une cholangite sclérosante, une pancolite de longue date (surtout si elle est apparue à un jeune âge) ou qui ont des antécédents familiaux de cancer colorectal. L'intervention est négligée en pratique clinique et pourtant elle offre une bonne solution de rechange à la surveillance par coloscopie chez les patients à risque élevé.
\end{abstract}

R eliable cost-benefit analyses require valid data. Such data are lacking in the case of colonoscopic surveillance programs for patients with ulcerative colitis (UC). Instead, we must rely on historical data, case series reported by clinicians with vested interests and inferences based on other patient groups. M odels can be constructed, but they are subject to wide variations in underlying assumptions (1). It is, therefore, very easy to make a case against colonoscopic surveillance in patients with U C. T his does not mean, however, that I recommend prophylactic colectomy for all patients with longstanding disease, even though there are subgroups for whom I seriously consider this option.

\section{MORBIDITY AND MORTALITY}

The main goal of surveillance colonoscopy in patients with UC is to prevent death from colorectal cancer (2). In theory, this goal can be attained by the detection of either dysplasia or early colon cancer, followed by curative surgery. U nfortunately, there are no randomized clinical trials comparing the mortality from colorectal cancer in patients with U C who have undergone colonoscopic surveillance, prophylactic colectomy or clinical follow-up without colonoscopy. We have only case series, usually from referral centres. They have generally involved a comparison of intermediate outcomes, such as Duke

This article was originally presented at a symposium entitled, "C ontroversies in G astroenterology", sponsored by A xcan Pharma, Toronto, 0 ntario, A pril 8 to 10, 2002

${ }^{1} \mathrm{U}$ nit of C linical E pidemiology, D epartment of M edicine, Karolinska H ospital, Stockholm, Sweden; ${ }^{2} \mathrm{D}$ epartment of E pidemiology, $\mathrm{H}$ arvard School of Public H ealth, Boston, M assachusetts, U SA

C orrespondence: Dr A Ekbom, D epartment of M edical E pidemiology, Karolinska Institutet, B ox 281, 17177 Stockholm, Sweden.

Telephone 46-8-08-728-61-90, fax 46-8-08-31-49-75, e-mail anders. ekbom@mep. ki. se 
stage, between cancers that are discovered by surveillance and those that are found clinically (3-6). A Iternatively, the duration of survival after a diagnosis of colorectal cancer can be determined for cancers detected within and outside of surveillance programs (3). These approaches, however, are susceptible to methodological problems, including the 'healthy worker' effect, surveillance bias and selection bias.

Patients enrolled in surveillance programs usually have been subjected to a clinical evaluation, including a barium enema and/or colonoscopy, before entering the program. Patients who are not selected for surveillance, or who refuse to enter a program, are probably not evaluated as thoroughly. Therefore, patients who enter programs tend to be healthier before enrolment than are other patients, making it difficult to compare the two groups.

It is impossible to determine the prevalence of asymptomatic neoplastic lesions in patients who have not undergone surveillance. This makes any comparison of the frequency of neoplastic lesions in surveyed and nonsurveyed patients invalid.

$M$ aintenance therapy with anti-inflammatory drugs, such as sulfasal azine or mesalazine, seems to decrease the risk of colorectal cancer in patients with UC $(7,8)$. There is evidence that patients in surveillance programs are more likely to comply with maintenance therapy than are those who do not undergo surveillance. Lynch et al (9) made the following observation: "A review of the notes of our cancer patients suggests that virtually none of them were on disease suppressive drugs, such as salazopyrine, regularly or at all."

The presence of this confounding factor puts into question any evaluation of the beneficial effect of surveillance programs.

Data from observational studies concerning the impact of surveillance colonoscopy on intermediate outcomes, such as cancer morbidity or dysplasia, should be interpreted with extreme caution. Bernstein et al (10) stated:

"A risk benefit ratio and cost-effectiveness of dysplasia surveillance cannot be properly analyzed with existing data. U ntil further studies are done that adequately address the limitations of existing studies, the true cost and benefit for the population as a whole remains unknown."

Since it was written in 1994, no new data have emerged that contradict this statement.

\section{WHAT DO WE KNOW?}

The following is a summary of some of the data that are relevant to this discussion:

1. Death from colorectal cancer accounts for the excess mortality in most follow-up studies of patients with UC (11).

2. Patients who undergo prophylactic colectomy will not die from colorectal cancer.

3. Follow-up studies have found that prophylactic colectomy does not adversely affect the quality of life of patients with UC (12)

4. Some patients in surveillance programs die from colorectal cancer $(3,5)$.
5. The only population-based study that found no excess in mortality from colorectal cancer was conducted in Copenhagen (13). The Danish investigators adopted a strategy of maintenance therapy with anti-inflammatory drugs and a low threshold for colectomy, but undertook no colonoscopic surveillance. A lthough it is impossible to gauge the relative benefits of colectomy and maintenance therapy on cancer mortality, the favourable results in this study are noteworthy.

6. Only one observational study, a case-control study from Sweden, assessed the effect of colonoscopic surveillance on mortality from colorectal cancer (14). There was a statistically insignificant trend toward benefit from surveillance, but it was very difficult to keep patients in the program. A high drop-out rate was noted after just one or two surveillance procedures. 0 ther investigators have found that patients who stop undergoing surveillance colonoscopy are much more likely to die from colorectal cancer than are those who remain in programs $(5,9)$. These reports do not necessarily reflect a ben eficial effect of surveillance; patients who withdraw from programs might also require fewer maintenance drugs or be less compliant with medical therapy.

It is, therefore, quite possible that colonoscopic surveillance is used mainly by patients who need it least. A $n$ unknown number of patients require alternative strategies, including prophylactic colectomy.

\section{WHO SHOULD UNDERGO PROPHYLACTIC COLECTOMY?}

There are at least four categories of $U C$ patients who should be seriously considered for prophylactic colectomy.

\section{Patients in whom dysplasia has been detected by} surveillance colonoscopy: Dysplasia is, by definition, a neoplastic lesion. Its presence signifies a high risk of colorectal cancer, either at the time of the initial biopsy or subsequently (15). Dysplasia will not disappear with follow-up colonoscopies, and there is no treatment that causes it to regress.

2. Patients with pancolitis of more than 10 years' duration, and in whom a history of colorectal cancer is present in a first degree relative: These patients have two independent risk factors for colorectal cancer. The risk is even greater if the first degree relative developed cancer before the age of 50 years (16). The importance of a family history of colorectal cancer to the risk of colitis-associated cancer has been confirmed in animal models (17).

3. Patients with primary sclerosing cholangitis: Patients with primary sclerosing cholangitis have an especially high risk of developing colorectal cancer. In a Swedish study, the cumulative incidence of colorectal cancer 10 years after the diagnosis of primary sclerosing cholangitis was $16 \%$ (18). 


\section{Patients with pancolitis and whose disease began before} age $\mathbf{1 5}$ years: A Ithough there still is controversy about the degree of risk in this group (19), these patients would harbour pancolitis for, on average, at least 60 years. There is no evidence that they would not be at high risk of cancer when they become older. Of note, one of the few deaths from colorectal cancer in the C openhagen study

(13) occurred in a patient in this subgroup.

Patients in these categories should be fully informed of the option of prophylactic colectomy.

\section{CONCLUSION}

Prophylactic colectomy is an underused procedure in patients with U C. Surveillance colonoscopy should not be considered the optimal approach to the prevention of colorectal cancer in these patients.

\section{REFERENCES}

1. Delcò F, Sonnenberg A . A decision analysis of surveillance for colorectal cancer in ulcerative colitis. G ut 2000;46:500-6.

2. Zack M M, Ekbom A, Persson PG, A dami H O. Evaluation of surveillance programmes for colorectal cancer in ulcerative colitis patients by case-control studies: M ethodological considerations. J M ed Screen 1997;4:137-41.

3. Choi PM, N ugent FW, Schoetz DJ Jr, Silverman M L, H aggitt RC. Colonoscopic surveillance reduces mortality from colorectal cancer in ulcerative colitis. G astroenterology 1993;105:418-24.

4. Löfberg R, Broström $O$, Karlén P, Tribukait B, Ö st A. Colonoscopic surveillance in long-standing total ulcerative colitis - A 15-year follow-up study. G astroenterology 1990;99:1021-31.

5. Lennard-Jones JE, M elville DM, M orson BC, Ritchie JK, W illiams C B. Precancer and cancer in extensive ulcerative colitis: Findings among 401 patients over 22 years. G ut 1990;31:800-6.

6. Lashner BA, Kane SV, H anauer SB. Colon cancer surveillance in chronic ulcerative colitis: $\mathrm{H}$ istorical cohort study. A m J G astroenterol 1990;85:1083-7.
7. Pinczowski D, Ekbom A, Baron J, Yuen J, A dami HO. Risk factors for colorectal cancer in patients with ulcerative colitis: A casecontrol study. G astroenterology 1994;107:117-20.

8. Eaden J, A brams K, Ekbom A, Jackson E, M ayberry J. Colorectal cancer prevention in ulcerative colitis: A case-control study. A liment Pharmacol Ther 2000;14:145-53.

9. Lynch DA F, Lobo A J, Sobala G M , Dixon M F, A xon AT. Failure of colonoscopic surveillance in ulcerative colitis. $G$ ut 1993:34:1075-80.

10. Bernstein $C N$, Shanahan $F$, W einstein W M . A re we telling patients the truth about surveillance colonoscopy in ulcerative colitis? Lancet 1994;343:71-4.

11. Ekbom A, H elmick C G, Zack M, H olmberg L, A dami H O. Survival and causes of death in patients with inflammatory bowel disease: A population-based study. $\mathrm{G}$ astroenterology 1992;103:954-60.

12. Thompson-Fawcett M W, Richard CS, O 'C onnor BI, Cohen $\mathrm{Z}$, M CLeod RS. Q uality of life is excellent after a pelvic pouch for colitis-associated neoplasia. Dis Colon Rectum 2000;43:1497-502.

13. Langholz E, M unkholm P, Davidsen M, Binder V. Colorectal cancer risk and mortality in patients with ulcerative colitis. Gastroenterology 1992;103:1444-51.

14. Karlén $P$, Kornfeld $D$, Broström 0 , Löfberg $R$, Persson PG Ekbom A . Is colonoscopic surveillance reducing colorectal cancer mortality in ulcerative colitis? A population based case control study. G ut 1998;42:711-4.

15. Lindberg $B$, Persson $B$, Veress $B$, Ingelman-Sundberg $H$, $\mathrm{G}$ ranqvist $\mathrm{S}$. Twenty years' colonoscopic surveillance of patients with ulcerative colitis. Detection of dysplastic and malignant transformation. Scand J G astroenterol 1996;31:1195-204.

16. A skling J, Dickman PW, Karlén P, Broström 0 , Lapidus A, Löfberg $R$, Ekbom A. Family history as a risk factor for colorectal cancer in inflammatory bowel disease. G astroenterology 2001;120:1356-62.

17. Bertone ER, G iovannucci EL, King N W Jr, Petto A J, Johnson LD. Family history as a risk factor for ulcerative colitis-associated colon cancer in cotton-top tamarin. G astroenterology 1998;114:669-74.

18. Kornfeld D, Ekbom A, Ihre T. Is there an excess risk for colorectal cancer in patients with ulcerative colitis and concomitant primary sclerosing cholangitis? A population based study. Gut 1997;41:522-5

19. Ekbom A. Risk factors and distinguishing features of cancer in IBD. Inflam Bowel Dis 1998:4:235-43. 


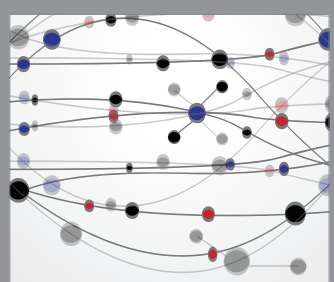

The Scientific World Journal
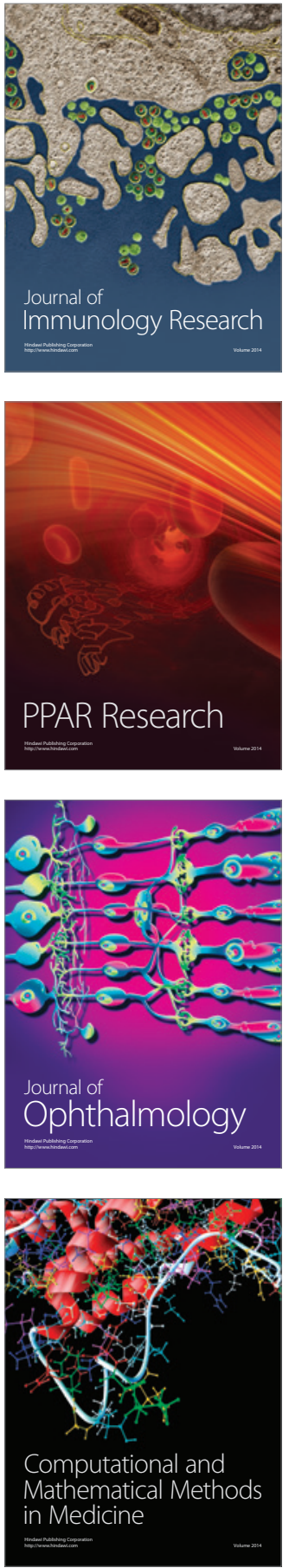

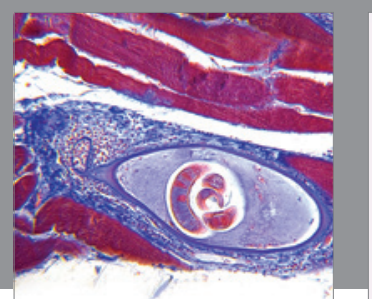

Gastroenterology Research and Practice

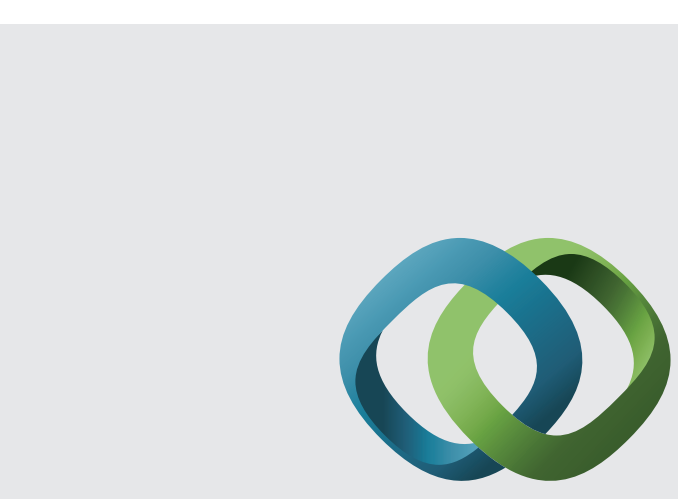

\section{Hindawi}

Submit your manuscripts at

http://www.hindawi.com
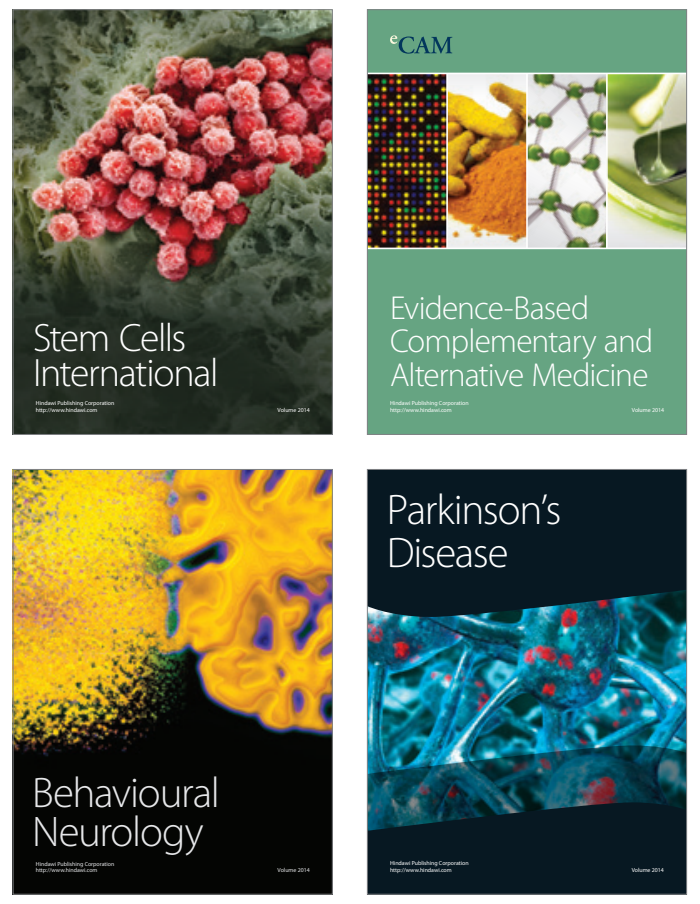
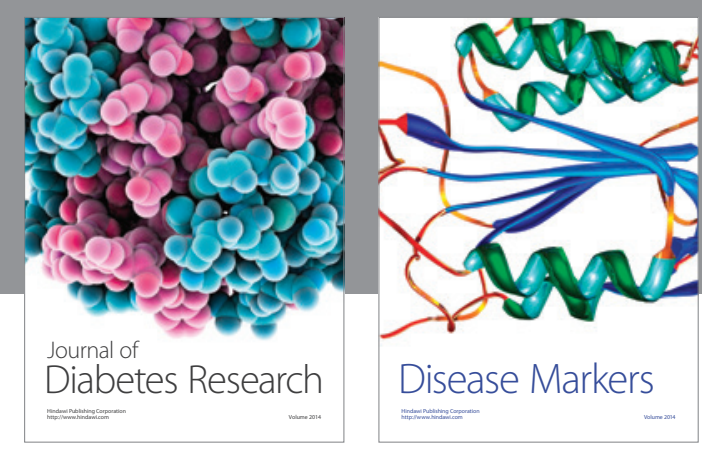

Disease Markers
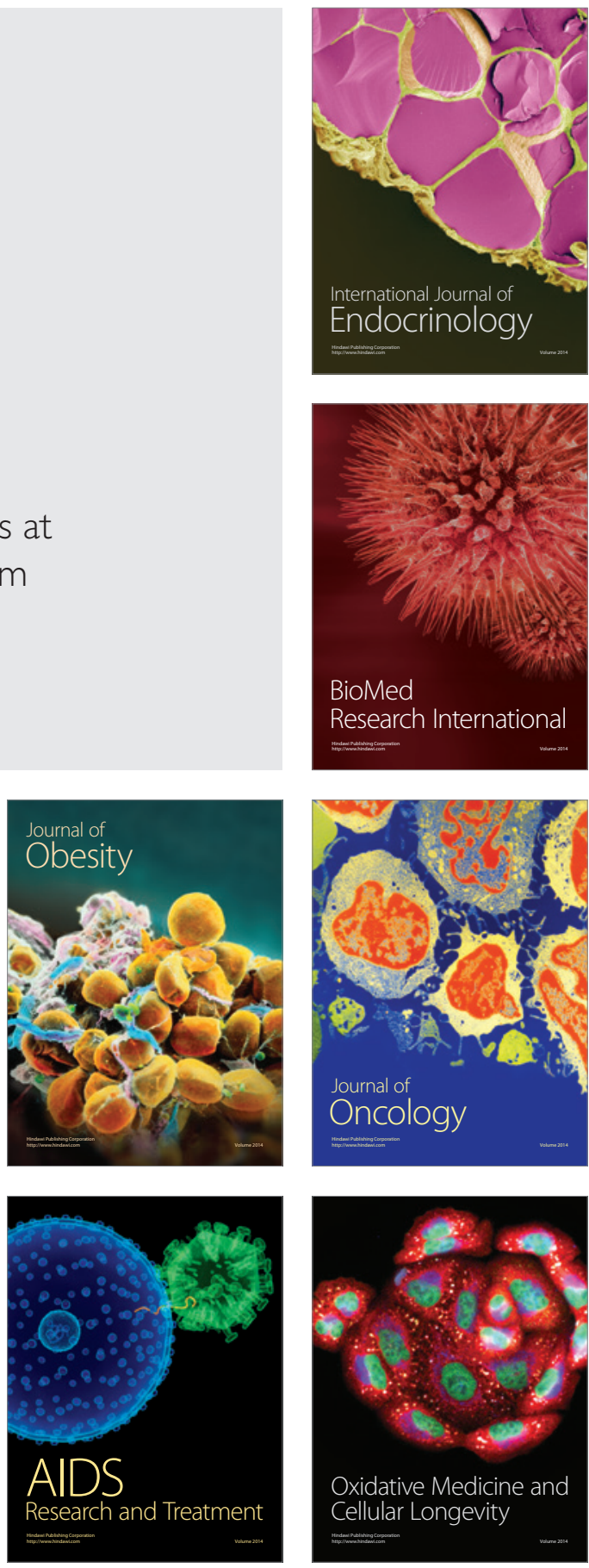